\title{
Individual behavioural traits not social context affects learning about novel objects in archerfish
}

\author{
Nick A. R. Jones ${ }^{1}$ (D) $\cdot$ Helen C. Spence-Jones ${ }^{1}$ (D) $\cdot$ Mike Webster $^{1}$ (D) $\cdot$ Luke Rendell $^{1}$ (D)
}

Received: 25 November 2020 / Revised: 9 February 2021 / Accepted: 12 February 2021 / Published online: 22 February 2021

(C) The Author(s) 2021

\begin{abstract}
Learning can enable rapid behavioural responses to changing conditions but can depend on the social context and behavioural phenotype of the individual. Learning rates have been linked to consistent individual differences in behavioural traits, especially in situations which require engaging with novelty, but the social environment can also play an important role. The presence of others can modulate the effects of individual behavioural traits and afford access to social information that can reduce the need for 'risky' asocial learning. Most studies of social effects on learning are focused on more social species; however, such factors can be important even for less-social animals, including non-grouping or facultatively social species which may still derive benefit from social conditions. Using archerfish, Toxotes chatareus, which exhibit high levels of intra-specific competition and do not show a strong preference for grouping, we explored the effect of social contexts on learning. Individually housed fish were assayed in an 'open-field' test and then trained to criterion in a task where fish learnt to shoot a novel cue for a food reward-with a conspecific neighbour visible either during training, outside of training or never (full, partial or no visible presence). Time to learn to shoot the novel cue differed across individuals but not across social context. This suggests that social context does not have a strong effect on learning in this non-obligatory social species; instead, it further highlights the importance that interindividual variation in behavioural traits can have on learning.
\end{abstract}

\section{Significance statement}

Some individuals learn faster than others. Many factors can affect an animal's learning rate-for example, its behavioural phenotype may make it more or less likely to engage with novel objects. The social environment can play a big role too-affecting learning directly and modifying the effects of an individual's traits. Effects of social context on learning mostly come from highly social species, but recent research has focused on less-social animals. Archerfish display high intra-specific competition, and our study suggests that social context has no strong effect on their learning to shoot novel objects for rewards. Our results may have some relevance for social enrichment and welfare of this increasingly studied species, suggesting there are no negative effects of short- to medium-term isolation of this speciesat least with regards to behavioural performance and learning tasks.

Keywords Social context $\cdot$ Inter-individual differences $\cdot$ Social learning $\cdot$ Toxotes $\cdot$ Exploratory tendency $\cdot$ Learning

Communicated by I. Hamilton

Nick A. R. Jones

narj@st-andrews.ac.uk

1 Centre for Social Learning and Cognitive Evolution, School of Biology, University of St Andrews, Sir Harold Mitchell Building, St Andrews, Fife KY16 9TH, UK

\section{Introduction}

Learning enables rapid responses to change (Shettleworth 1972, 2009), but in order to learn about a novel object, an animal must first engage with it. Exploring a potential new food source can provide obvious foraging benefits but may expose an individual to potential risk from predation or noxious substances (Lima and Dill 1990). The social environment 
can play a large role in an individual's motivation to engage with novelty and subsequent learning opportunities (Boogert et al. 2006; Mirville et al. 2016; Langley et al. 2018; Kent et al. 2019; Hansen et al. 2020). Individuals can be more likely to approach novel foods with conspecifics present (GómezLaplaza and Morgan 1986; Sherwin 2003). For example, capuchin monkeys (Cebus apella) in social conditions had higher levels of engagement with and consumption of novel foods than solitary individuals (Visalberghi and Fragaszy 1995). Being in a group also affords learning opportunities through social learning mechanisms (Coussi-Korbel and Fragaszy 1995; Hoppitt and Laland 2013; Ward and Webster 2016) such as social facilitation (Zentall and Hogan 1976; Dindo et al. 2009). The social environment can also enhance learning effects through the 'social buffering of stress' (Smith et al. 1998; DeVries et al. 2003; Allen et al. 2009; Crane et al. 2018; Culbert et al. 2019), for example cichlids (Cichlasoma paranaense) in groups showed lower stress and faster learning rates than isolated individuals (Brandão et al. 2015). These social benefits are not limited to obligate social species. The solitary octopus (Octopus vulgaris) (Fiorito and Scotto 1992) and several nongrouping species of fish (Webster and Laland 2017), including solitary sharks (Vila Pouca and Brown 2019; Vila Pouca et al. 2020), use social learning. However, the effects of the social environment on learning can be complex.

Learning performance can depend on the social dynamics (Nicol and Pope 1999; Soma and Hasegawa 2004; Boogert et al. 2006; Grampp et al. 2019), behavioural traits (An et al. 2011; González-Bernal et al. 2014; Krueger et al. 2014), sex (Snijders et al. 2019) and level of familiarity (Guillette et al. 2016) of the individuals involved. In some species, individuals show no benefit from the presence of others when learning, for example the facultatively social tree skinks, Egernia striolata, (Riley et al. 2017, 2018). The presence of conspecifics can even worsen learning performance (Zajonc et al. 1969; Webster and Laland 2012; Fei et al. 2019).

Notwithstanding social factors, individual variation can also have significant effects on learning. Many of the commonly measured behavioural traits and syndromes relate to exploratory tendency and associated neophobia (aversion to novelty (Greenberg and Mettke-Hofmann 2001; Mettke-Hofmann 2017)), and these traits can affect learning, as well as cognitive performance more generally (Sih and Del Giudice 2012; Greggor et al. 2015; Morand-Ferron et al. 2016; Boogert et al. 2018; Dougherty and Guillette 2018). Several studies have shown that individuals which exhibit consistently high levels of exploratory tendency tend to show lower levels of neophobia and engage with/learn-to-associate cues with food rewards more quickly than individuals with low activity levels (An et al. 2011; Guenther et al. 2014; Guillette et al. 2015; Reader 2015; Mazza et al. 2018). Differences in response to stress and physiology may drive variation in learning.
Individuals exhibiting specific 'coping styles' (Koolhaas et al. 1999) can perform differently in cognition studies (Zidar et al. 2017; Mazza et al. 2019). Several studies have shown that 'proactive' individuals, with low cortisol levels and high levels of exploratory activity, learn faster than 'reactive' individuals which tend to take longer to approach novel objects (Mesquita et al. 2015; Bensky et al. 2017; Raoult et al. 2017). These individual differences in behavioural traits can be moderated by social environment (Webster and Ward 2011; Jolles et al. 2016; Pearish et al. 2019; Tucker and Suski 2019); however, the importance of social context may depend on the species.

Studies exploring the effects of social context on learning have focused on relatively few highly social species, and there is current debate about the evolution of social learning on social and non-social species (Heyes 2012; Reader 2016). We were interested in exploring whether social context would facilitate learning in a species not generally considered social but capable of receiving social information, and whether this could overcome pre-existing variation in relevant traits such as exploratory tendency. Specifically, we tested the effect of different social context on the rate of learning an association between shooting novel objects and obtaining a food reward in archerfish, Toxotes chatareus. Famous for their ability to 'shoot' down prey (Bekoff and Dorr 1976; Dill 1977; Schuster 2007), archerfish exhibit low sociality with no grouping preference (Timmermans and Maris 2000), possibly linked to their highly competitive foraging behaviour (Rischawy et al. 2015) and tendency for intra-specific kleptoparasitism (Davis and Dill 2012). Previous work has suggested that they use social information (Schuster et al. 2006) and alter their shooting behaviour in response to a conspecific in a neighbouring tank (Jones et al. 2018). However, little else is known about their social behaviour and social effects on learning. Most research has focused on understanding the mechanisms underlying their shooting abilities (Timmermans and Vossen 2000; Gerullis and Schuster 2014; Reinel and Schuster 2018) and related abilities (Ben-Tov et al. 2018; Newport and Schuster 2020) including image search (Temple et al. 2010; Rischawy and Schuster 2013; Ben-Tov et al. 2015) and associated neurobiology (Schlegel and Schuster 2008; Ben-Simon et al. 2012; Machnik et al. 2018a, b). Archerfish have been shown to exhibit consistent individual differences in latency to shoot - with consequences for their performance in learning and discrimination trials (Jones et al. 2020): fish with low latencies were quicker to learn to shoot targets for reward. The effects of these individual differences have only been explored in fish in solitary conditions, and no social element has been tested. Our main question in this study was whether archerfish learn to shoot a novel object faster when housed in solitary conditions or with a visible conspecific. We included a variation of the open-field assay to determine whether individual variation in learning rates was also associated with individual differences in exploratory tendency. 


\section{Methods}

\section{Subjects}

We tested 19 archerfish, T. chatareus, $12 \pm 0.5 \mathrm{~cm}$ (total length), from animals housed at the University of St. Andrews. All fish were wild-caught as juveniles from a freshwater population, sourced from an accredited ornamental fish supplier. Fish were of unknown sex as archerfish are sexually monomorphic. The fish had been kept in their stock tanks for a minimum of 6 months prior to use in the study and had not been trained to shoot or exposed to experimental tanks in that time. Stock tanks $(180 \times 45 \mathrm{~cm}$ and $35 \mathrm{~cm}$ deep $)$ held at temperatures between 25 and $26^{\circ} \mathrm{C}$ under a 12:12 h light:dark cycle, had environmental enrichment in the form of $3-\mathrm{cm}$ deep gravel substrate and several plastic plants. Water quality parameters ( $\mathrm{pH}$, nitrite, ammonia and nitrate concentrations) were measured weekly, and levels were kept within a range appropriate for archerfish (Newport et al. 2013; Jones et al. 2018), using external canister filters and regular water changes.

Each of four stock tanks held between 5 and 8 fish, with a total of 27 fish. We aimed to test groups of familiar fish so we selected 21 fish for the experiment to ensure all groups of fish came from the same stock tank. At the time of the experiment, the fish were estimated to be 18-24 months old, based on their size and date of arrival from the retailer; however, this is an estimate as the correlation between age and growth rate in captivity is not known for this species. The fish were fed daily with an alternating mixture of commercial fish food (Tetra Cichlid Sticks) and freeze-dried bloodworms. When moving fish into the experimental setup, fish were always captured from the same tank. Fish were measured as they were captured from the stock tank - using a ruler taped to the side of the tank, netted fish were gently pressed against the side of the tank to record their length before being moved to the experimental tank. All the fish that were tested were used only once in this experiment.

\section{General procedure}

Fish were tested in groups of three; each fish in a tested trio came from the same stock tank and had been kept together for at least 6 months prior to the experiment to ensure they were familiar with each other. Each fish was moved from the stock tank and introduced into one of three experimental tanks which had been randomly assigned to one of the social treatments. Each fish was then given a full day to acclimate to the experimental tank. After $24 \mathrm{~h}$, the video recordings were taken for the behavioural assay. At the time of introduction and until after the behavioural assay, all barriers were kept in place such that all fish were in the same solitary conditions with no other fish visible to them.
Between 46 and $48 \mathrm{~h}$ after being moved into experimental tanks, the barriers were re-positioned in accordance with the social treatment assigned to each tank. Fish were then given another period of $\sim 24 \mathrm{~h}$ acclimation to the conditions of their respective social treatment before training began. During the training period, the fish were trained to learn to shoot at a novel target to obtain a food reward. Archerfish will readily shoot novel targets and can learn to associate shooting a target with receiving food rewards (Newport et al. 2013; Karoubi et al. 2017). Each fish was given a single training session per day until it reached the training criterion: 10 on-target shots a day for two consecutive days. In each session, an initially novel target (a five-armed star-shaped cut from black plastic, max diameter $2 \mathrm{~cm}$ ) was placed on the glass $15 \mathrm{~cm}$ above the water level of the tank. A training session lasted $45 \mathrm{~min}$, or until a fish had shot at the target 10 times. Shots were easily visible as they left water droplets on the underside of the transparent platform on which the target was placed, signalling where the shot had impacted. A shot was considered on-target if it was within $2 \mathrm{~cm}$ of the target; successful shots were rewarded with food, and the target was removed and repositioned on the glass for a subsequent trial. We continued training for all fish in each set until all three of the fish had reached the criterion or until the 50th session. Fish were given a maximum of 50 sessions to reach the criterion.

\section{Experimental setup}

Experimental tanks ( $55 \times 55 \mathrm{~cm}$ and $45 \mathrm{~cm}$ deep) were each set up with an immersion heater (kept at $24.5 \pm 0.5^{\circ} \mathrm{C}$ ), a small internal filter (Eheim Biopower 200 Internal Filter), a 1-cmdeep gravel bottom, and plastic plants (positioned to provide structure and refuge but allow a clear view of neighbouring tanks). We used two replicate setups of three tanks each to run up two groups of fish at a time. In each setup, three tanks were set up side by side with a $0.5-\mathrm{cm}$ gap between them, using the same setup as in Jones et al. (2018) (see Fig. 1). A 3-mm-thick black opaque plastic barrier could be easily inserted between each tank to block or allow vision between tanks. The barriers were used to create different social conditions detailed below, by controlling the visibility of the side tanks.

\section{Behavioural assay}

We scored fish in their experimental tanks using a simple 'open-field' assay. The 'open-field test' exposes animals to a novel area and allows measurements such as amount of activity and time spent in the open as a measure of exploratory behaviour, where animals that spend more time in the open are considered to have greater exploratory behaviour (Burns 2008). This assay is widely used in fishes (Webster et al. 2007; Chapman et al. 2011; Conrad et al. 2011; Lucon-Xiccato et al. 2020). For this assay, each fish was recorded for $10 \mathrm{~min}$, and 


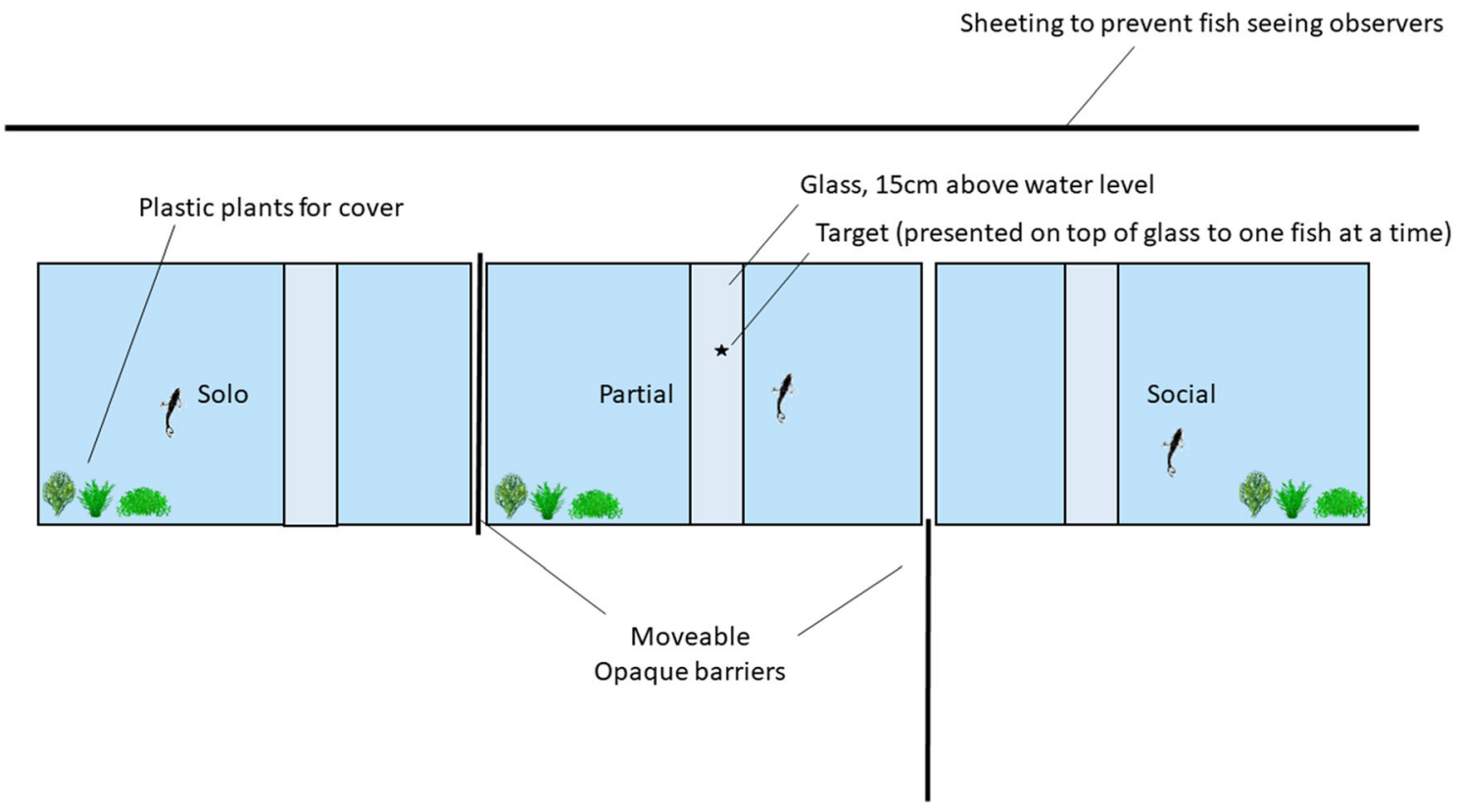

Fig. 1 Experimental set-up, from a top-down view as recorded by the camera above the tanks. The different experimental treatments and level of social context was manipulated by use of the opaque barriers. Solo treatments were always set up in one of the two end tanks

the proportion of time spent in the open, where the fish was more than 1 body length away from the plant shelter or corners of the tank, was recorded. We used a 24-h acclimation period prior to conducting the assay, informed by our previous work with this species in a similar setup (Jones et al. 2018); while a single measurement per individual is not ideal for a labile trait (Biro and Stamps 2010), suitable acclimation periods can provide more robust estimates of individual behavioural traits (Biro 2012), as demonstrated by high estimates of repeatability in guppy activity levels following acclimation (O'Neill et al. 2018). To minimize observer bias, blinded methods were used; specifically, a hypothesis naïve scorer was used to score videos of the behavioural assays.

We initially planned on testing 21 fish, but the social context of two fish (in a solo and partial treatment) may have been compromised as there was a gap in the barrier between the two tanks for at least one session. We noticed this on day 4 of testing this group. These two fish were excluded from the data and were not tested further except to provide a social context for the fish in the social treatment. Of the remaining 19 fish tested, one - in the social treatment - was unable to hit the target or shoot within $2 \mathrm{~cm}$ of it. This fish showed no obvious injury or morphological difference from other fish but was unable to reach training criterion for this reason. All other fish were able to shoot and hit the target.

\section{Experimental treatments (social context)}

The opaque barriers were employed to block visible contact between fish in neighbouring tanks. Fish in the 'solo' treatment were left in isolation, with no visible neighbour. In the 'partial' treatment, fish had partial social exposure: they were able to see a neighbouring fish when given opportunities to shoot the presented target. However, they could not observe when the neighbour was being trained. Fish in the partial treatment were therefore not exposed to social information about the presented target and associated food reward by other fish, but they may have been impacted by the presence of another fish. This presence could have had either positive impacts on learning rates through social buffering of stress, or, more likely, negative impacts due to the presence of potential competitors per (Simon et al. 2011; Jones et al. 2018). Fish in the 'social' treatment were exposed to full social conditions and had visible contact with a neighbouring fish at all times (including during the neighbour's training sessions), except when presented with the target itself. A visible neighbour fish may act as a potential distraction when shooting, as shown by Jones et al. (2018), so the social condition was designed to afford social information about the target while reducing the chance of distraction. The treatments were pseudo-randomly assigned to each tank prior to transferring fish into them. For each trio of fish tested, the solo treatment was randomly assigned to one of the two end tanks: the social and partial treatments were then randomly allocated a tank from the two remaining.

\section{Statistical analyses}

All analysis was conducted using $\mathrm{R}$ base package (R Core Team 2019) and specific packages as detailed below.

In order to determine whether the different treatments affected learning rates, we conducted a survival analysis using a Cox 
proportional hazards regression model, as per similar studies exploring time to reach the criterion in learning tasks (Bensky and Bell 2018). We used this approach as six of the 19 fish failed to reach criterion in the given 50 sessions. The numbers of sessions required to reach training criterion were used as the dependent variable. The social treatment (solo, partial, or social) and score from the behavioural assay (the proportion of time spent in the open) were the two independent variables included in the models. We fitted a model using the coxph function in the 'survival' package in R (Therneau 2019), with the variables detailed above, where survival equated to failing to reach the learning criterion. We included an interaction between the two independent variables, as we expected that the effect of social treatment may depend on the behavioural traits of individual fish. This analysis allowed us to explore the effects of the independent variables of interest on the probability of reaching learning criterion using all the available data.

\section{Results}

There was no effect of social context on the probability of reaching the learning criterion (Table 1; Fig. 2); however, the probability of an individual reaching criterion did depend on the proportion of time that the individual spent in the open in the open-field assay. Time spent in the open during the initial behavioural assay is significantly associated with time to learn: greater time spent in the open, our measure of exploratory tendency, is associated with increased learning rates (Table 1; Fig. 3).

\section{Discussion}

The social environment did not influence the associative learning rates of the archerfish in this experiment. Instead, learning rates were related to behavioural traits linked to exploratory tendency - specifically, time spent in the open in an open-field test. Fish which spent more time in the open (i.e.,

Table 1 Summary output of survival model

\begin{tabular}{lclll}
\hline & Coef $(\beta)$ & SE (coef) & $z$ & $\operatorname{Pr}(>|z|)$ \\
\hline Social treatment & 2.411 & 1.735 & 1.389 & 0.1648 \\
Solo treatment & 1.181 & 1.422 & 0.83 & 0.4063 \\
Open-field score & $\mathbf{1 1 . 1 4}$ & $\mathbf{5 . 1 5 4}$ & $\mathbf{2 . 1 6 2}$ & $\mathbf{0 . 0 3 0 7}$ \\
Social: open-field score & -10.77 & 6.292 & -1.711 & 0.0871 \\
Social: open-field score & 2.911 & 4.466 & 0.652 & 0.5146 \\
\hline
\end{tabular}

Positive coefficients are associated with shorter time to reach learning criterion. Significant coefficients $(p<0.05)$ are highlighted in bold. Likelihood ratio test $=16.61$ on $5 d f, p=0.005$, concordance $=0.724$ were more exploratory) were faster learners, taking fewer sessions on average to reach the criterion.

The link between individual behavioural traits and learning rates is apparent in an increasing number of species (Dougherty and Guillette 2018; Smit and van Oers 2019); our results complement earlier findings showing that inter-individual differences in latency to shoot relate to differences in learning in archerfish (Jones et al. 2020). Our inability to detect any effect of social context on learning rates is perhaps more interesting given that archerfish were affected by the presence of others in a previous experiment with similar conditions and setup: visible conspecifics in a neighbouring tank increased the latency to shoot and behaviour of shooting fish (Jones et al. 2018). It certainly raises more questions: is there no effect of social context on learning, or are these effects more subtle and therefore masked by the individual differences? Our limited sample size prevents us from being able to address this issue. Effects of social environment on learning can vary with behavioural phenotype where more exploratory individuals tend (relative to less exploratory individuals) to be less sensitive to external stimuli (Guillette et al. 2011; Kelly et al. 2020) and derive less benefit from social environment (Barou Dagues et al. 2020). The lack of significant effect in our study may therefore be a result of exploratory fish that are more likely to engage in risk-taking behaviour but less likely to use social information. Five fish that did not reach training criterion in the allotted time (but could shoot), and it is possible that these individuals may have been more affected by different social contexts. Given the large variation between individuals we found, future studies with a greater sample size will be needed to detect any social effects in less exploratory, potentially more socially sensitive fish, or at least be more confident that there is no social effect on learning to shoot a novel target in this species. Our results, however, do correspond with other studies, across several different species, which have shown that social context does not always have a strong effect on learning performance, at least not when there are strong inter-individual differences in behavioural traits (Seferta et al. 2001; Krueger et al. 2014; Riley et al. 2017, 2018).

Despite the potential benefits of social learning, public information use appears to be species-specific (Webster et al. 2019), and individual biases can have a greater effect on learning than social information even when it is employed (Szabo et al. 2017). Even in species known to use social information, social learning may be dependent upon an individual having some experience with novel foraging opportunities, as recently shown in American crows (Corvus brachyrhynchos) (Pendergraft et al. 2020) and stickleback species (Webster and Laland 2018). While it is likely that archerfish do use social information, given previous findings suggesting social learning in this species (Schuster et al. 2006), many factors may impact the use of social leaning or our ability to detect it. Especially, as both social and asocial learning may depend on the same basic mechanisms (Heyes 2012) and factors that 


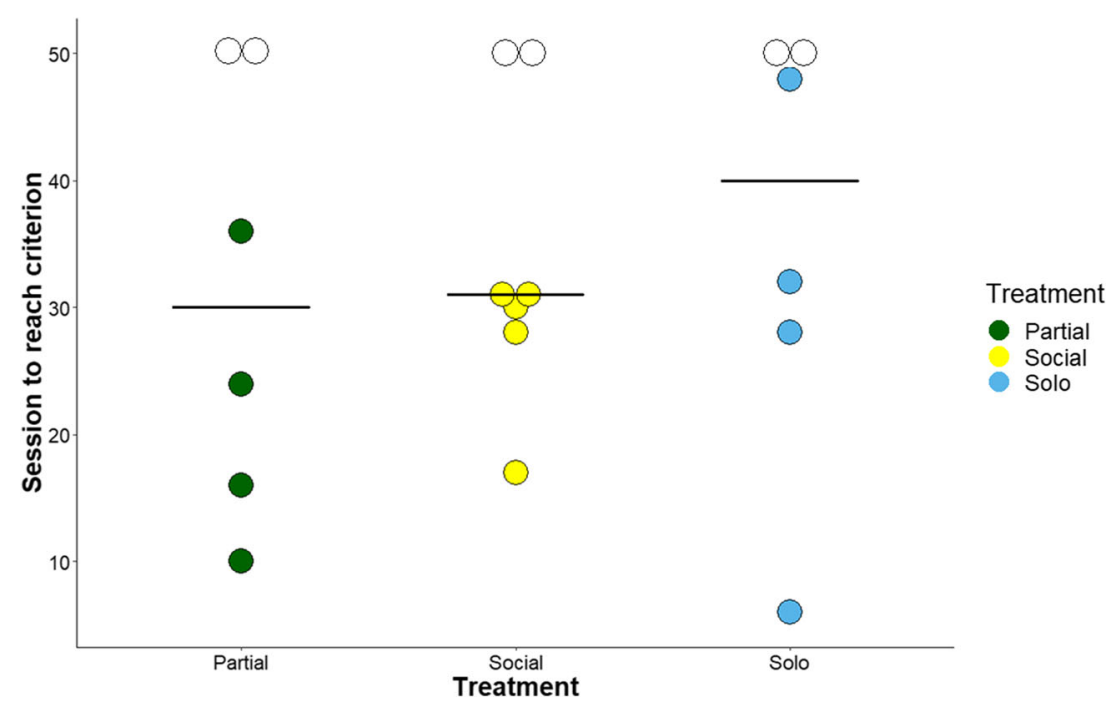

Fig. 2 Effect of different social contexts on time taken to reach training criterion. The treatments relate to level of exposure to a visible conspecific: solo (no social exposure); partial (visual social contact except during training of neighbours); social (full visual social contact including during training of neighbours). Only fish with 'social' exposure

constrain learning (Shettleworth 1972). In addition to showing no preference for shoaling with conspecifics as juveniles (Timmermans and Maris 2000), archerfish are highly competitive predators (Rischawy et al. 2015). Intra-specific competition can be a major driver of individual differences in behaviour, with stronger competition potentially leading to more defined inter-individual differences (Bolnick et al. 2003; Svanbäck and Bolnick 2007; Laskowski and Bell 2013) and archerfish like other predators show strong inter-individual variation in latency to respond to and attack prey (SzopaComley et al. 2020a, b). These individual differences may override effects of the social environment, particularly in social species-as shown in threespine sticklebacks (Gasterosteus aculeatus) where, individual differences were had access to social information regarding the novel objects and associated food rewards. Black lines indicate median number of sessions to reach criterion for each treatment; coloured dots represent data points for individual fish. White points indicate fish which failed to reach criterion within 50 sessions

suppressed in certain social contexts, but bolder individuals were more likely to feed first in social conditions (McDonald et al. 2016). Our experimental design limited our ability to detect more subtle effects or interactions of this nature. Archerfish do respond to the presence of other fish by increasing their latency to shoot (Jones et al. 2018) and exhibit lower shooting accuracy in the presence of others (Simon et al. 2011). This may have impacted training results of fish in the partial social condition, the only condition in which subject fish were exposed to a visible conspecific when given opportunities to shoot. The presence of other fish may have inhibited learning through distraction by the conspecific (as demonstrated in zebrafish Dario rerio; Ayoub et al. 2019) or inhibition from potential conspecific competition.
Fig. 3 Relationship between the proportion of time spent in the open and number of sessions taken to reach training criterion. Each point represents a single fish that reached criterion $(n=13)$ and is coloured according to the social treatment they were exposed to. The predicted response and estimated standard error from a linear model are given by the black line and grey shading, respectively

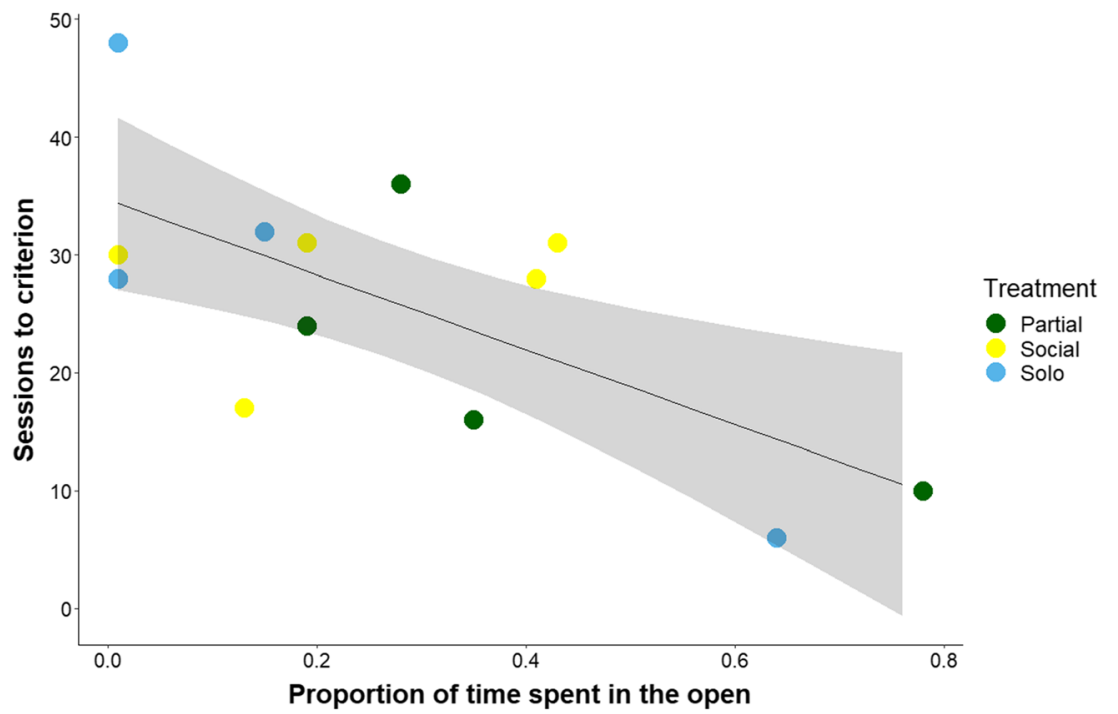


One area where our results may be useful is in informing future studies, particularly with regard to acclimation, training and related ethical and welfare concerns. Archerfish, like other animals perhaps especially other wild caught animals - which may be slower or less likely to engage with novel objects than captive-bred or urban individuals (Gajdon et al. 2004; Jarjour et al. 2020)—can require extended periods to acclimate and train (Archard and Braithwaite 2010; Patton and Braithwaite 2015). Acclimation can play an important role in the expression of behaviours and performance in behavioural assays (O'Neill et al. 2018), and sufficient acclimation may help reduce the issues inherent in measuring cognition in the laboratory (Webster and Rutz 2020). Cognition studies may be particularly susceptible to factors affecting stress and environmental conditions which can affect measures (Pritchard et al. 2016), and this is especially important when exploring consistent individual variation (Strand et al. 2010; Rowe and Healy 2014; Griffin et al. 2015; White et al. 2017; Boogert et al. 2018; da Silva et al. 2020). There have been no studies of archerfish welfare, and further work into social and environmental enrichment is required, but our study suggests that keeping archerfish alone may not be detrimental to their welfare in the short term. Learning rates are one measurable aspect of animal welfare and benefit of enrichment (Strand et al. 2010) and the lack of visible conspecifics had no negative effects on learning rates in our study, for the fish that completed training. However, it also suggests that the relatively long training and acclimation periods required for learning in this species may not be easily reduced by including a visible conspecific. This may be important for other species where social effects are relatively unstudied, and where they are likely to be increasingly used as a model species.

Archerfish are not a highly social species but do modify their shooting behaviour in response to the presence of conspecifics. The lack of variation in learning rates with social context in this study suggests that learning about what to shoot and the decision to take a shot may not be affected equally by social factors. Other non-grouping species may similarly be less likely to show strong effects of social context on learning behaviour, even when their behaviour can be affected by social context in other situations.

Acknowledgements Thank you to Edith Invernizzi, Ella AckroydWeldon and Dagmar Der Weduwen for helping with fish husbandry. Thank you to Tania Mendo and both anonymous reviewers for useful comments which allowed us to improve the manuscript.

Availability of data The data analysed for this study are available at: https://osf.io/us9t7/?view_only=743ea515b7ff4201b16dd7ed896edff9.

Author contribution NARJ, MW, and LR designed the study. NARJ and HCS-J collected the data. NARJ conducted the analyses. HCS-J acted as initially naïve video scorer. NARJ wrote the manuscript. All authors edited and commented on the paper.
Funding This study was funded by the Fisheries Society of the British Isles (studentship to NARJ).

\section{Declarations}

Ethics approval This research was approved by the University of St Andrews Animal Welfare and Ethics Committee (AWEC). No procedures required U.K. Home Office licensing. All tanks were enriched with gravel and plastic plants for cover. All fish were retained in the laboratory after the study period to be used in future projects. Handling was kept to a minimum, and when fish had to be moved between tanks, they were caught using two large hand nets to reduce the likelihood of extended capture periods. In the experimental tanks, fish were kept singly in a volume of at least 1251 . Archerfish are not considered a social species. There are no published studies on the effects or preference for any social context and or isolation in this species, but several previous studies have maintained archerfish in isolation with no reported ill effects or perceived likelihood of stress (Gabay et al. 2013; Gerullis and Schuster 2014; Newport et al. 2014, 2018). During our study, we closely monitored each fish, specifically for signs of reduced feeding rate, responsiveness, stereotypic behaviour and colour changes. We observed few instances of these signs: all of the instances of short-term colour change occurred immediately post-transfer between tanks and reduced feeding rate for the first $12 \mathrm{~h}$ post-transfer.

Consent for publication All authors consent to publication of this article.

Conflict of interest The authors declare no conflict of interest.

Open Access This article is licensed under a Creative Commons Attribution 4.0 International License, which permits use, sharing, adaptation, distribution and reproduction in any medium or format, as long as you give appropriate credit to the original author(s) and the source, provide a link to the Creative Commons licence, and indicate if changes were made. The images or other third party material in this article are included in the article's Creative Commons licence, unless indicated otherwise in a credit line to the material. If material is not included in the article's Creative Commons licence and your intended use is not permitted by statutory regulation or exceeds the permitted use, you will need to obtain permission directly from the copyright holder. To view a copy of this licence, visit http://creativecommons.org/licenses/by/4.0/.

\section{References}

Allen PJ, Barth CC, Peake SJ, Abrahams MV, Anderson WG (2009) Cohesive social behaviour shortens the stress response: the effects of conspecifics on the stress response in lake sturgeon Acipenser fulvescens. J Fish Biol 74:90-104. https://doi.org/10.1111/j.10958649.2008.02112.x

An YS, Kriengwatana B, Newman AE, MacDougall-Shackleton EA, MacDougall-Shackleton SA (2011) Social rank, neophobia and observational learning in black-capped chickadees. Behaviour 148:5569. https://doi.org/10.1163/000579510X545829

Archard GA, Braithwaite VA (2010) The importance of wild populations in studies of animal temperament. J Zool 281:149-160. https://doi. org/10.1111/j.1469-7998.2010.00714.x

Ayoub R, Armstrong E, Miller NY (2019) Out of sight, out of mind: mechanisms of social choice in fish. Animal Behaviour 155:163169. https://doi.org/10.1016/j.anbehav.2019.05.025

Barou Dagues M, Hall CL, Giraldeau L-A (2020) Individual differences in learning ability are negatively linked to behavioural plasticity in a 
frequency-dependent game. Anim Behav 159:97-103. https://oi. org/10.1016/j.anbehav.2019.11.011

Bekoff M, Dorr R (1976) Predation by "shooting" in archer fish, Toxotes jaculatrix: accuracy and sequences. Bull Psychon Soc 7:167-168. https://doi.org/10.3758/BF03337154

Ben-Simon A, Ben-Shahar O, Vasserman G, Ben-Tov M, Segev R (2012) Visual acuity in the archerfish: behavior, anatomy, and neurophysiology. J Vision 12:18. https://doi.org/10.1167/12.12.18

Bensky MK, Bell AM (2018) Intraspecific variation in cue-specific learning in sticklebacks. Anim Behav 137:161-168. https://doi.org/10. 1016/j.anbehav.2018.01.003

Bensky MK, Paitz R, Pereira L, Bell AM (2017) Testing the predictions of coping styles theory in threespined sticklebacks. Behav Process 136:1-10. https://doi.org/10.1016/j.beproc.2016.12.011

Ben-Tov M, Donchin O, Ben-Shahar O, Segev R (2015) Pop-out in visual search of moving targets in the archer fish. Nat Commun 6: 6476. https://doi.org/10.1038/ncomms 7476

Ben-Tov M, Ben-Shahar O, Segev R (2018) What a predator can teach us about visual processing: a lesson from the archerfish. Curr Opin Neurobiol 52:80-87. https://doi.org/10.1016/j.conb.2018.04.001

Biro PA (2012) Do rapid assays predict repeatability in labile (behavioural) traits? Anim Behav 83:1295-1300. https://doi.org/ 10.1016/j.anbehav.2012.01.036

Biro PA, Stamps JA (2010) Do consistent individual differences in metabolic rate promote consistent individual differences in behavior? Trends Ecol Evol 25:653-659. https://doi.org/10.1016/j.tree.2010.08.003

Bolnick DI, Svanbäck R, Fordyce JA, Yang LH, Davis JM, Hulsey CD, Forister ML (2003) The ecology of individuals: incidence and implications of individual specialization. Am Nat 161:1-28. https:// doi.org/10.1086/343878

Boogert NJ, Reader SM, Laland KN (2006) The relation between social rank, neophobia and individual learning in starlings. Anim Behav 72:1229-1239. https://doi.org/10.1016/j.anbehav.2006.02.021

Boogert NJ, Madden JR, Morand-Ferron J, Thornton A (2018) Measuring and understanding individual differences in cognition. Phil Trans $\mathrm{R}$ Soc B 373:20170280. https://doi.org/10.1098/rstb.2017.0280

Brandão ML, Braithwaite VA, Gonçalves-de-Freitas E (2015) Isolation impairs cognition in a social fish. Appl Anim Behav Sci 171:204 210. https://doi.org/10.1016/j.applanim.2015.08.026

Burns JG (2008) The validity of three tests of temperament in guppies (Poecilia reticulata). J Comp Psychol 122:344-356. https://doi.org/ 10.1037/0735-7036.122.4.344

Chapman BB, Hulthén K, Blomqvist DR, Hansson LA, Nilsson JA, Brodersen J, Anders Nilsson P, Skov C, Brönmark C (2011) To boldly go: individual differences in boldness influence migratory tendency. Ecol Lett 14:871-876. https://doi.org/10.1111/j.14610248.2011.01648.x

Conrad JL, Weinersmith KL, Brodin T, Saltz JB, Sih A (2011) Behavioural syndromes in fishes: a review with implications for ecology and fisheries management. J Fish Biol 78:395-435. https://doi.org/10.1111/j.1095-8649.2010.02874.x

Coussi-Korbel S, Fragaszy DM (1995) On the relation between social dynamics and social learning. Anim Behav 50:1441-1453. https:// doi.org/10.1016/0003-3472(95)80001-8

Crane AL, Bairos-Novak KR, Sacco LH, Ferrari MCO (2018) The socially mediated recovery of a fearful fish paired with periodically replaced calm models. Proc R Soc B 285:20180739. https://doi.org/ 10.1098/rspb.2018.0739

Culbert BM, Gilmour KM, Balshine S (2019) Social buffering of stress in a group-living fish. Proc R Soc B 286:20191626. https://doi.org/10. 1098/rspb.2019.1626

da Silva A, Lima MR, Meletti PC, Jerep FC (2020) Impact of environmental enrichment and social group size in the aggressiveness and foraging activity of Serrapinnus notomelas. Appl Anim Behav Sci 224:104943. https://doi.org/10.1016/j.applanim.2020.104943
Davis BD, Dill LM (2012) Intraspecific kleptoparasitism and countertactics in the archerfish (Toxotes chatareus). Behaviour 149:13671394. https://doi.org/10.1163/1568539X-00003026

DeVries AC, Glasper ER, Detillion CE (2003) Social modulation of stress responses. Physiol Behav 79:399-407. https://doi.org/10. 1016/S0031-9384(03)00152-5

Dill LM (1977) Refraction and the spitting behavior of the archerfish (Toxotes chatareus). Behav Ecol Sociobiol 2:169-184. https://doi. org/10.1007/BF00361900

Dindo M, Whiten A, de Waal FBM (2009) Social facilitation of exploratory foraging behavior in capuchin monkeys (Cebus apella). Am J Primatol 71:419-426. https://doi.org/10.1002/ajp.20669

Dougherty LR, Guillette LM (2018) Linking personality and cognition: a meta-analysis. Phil Trans R Soc B 373:20170282. https://doi.org/10. 1098/rstb.2017.0282

Fei X-Y, Liu S, Sun Y-H, Cheng L (2019) Social isolation improves the performance of rodents in a novel cognitive flexibility task. Front Zool 16:43. https://doi.org/10.1186/s12983-019-0339-4

Fiorito G, Scotto P (1992) Observational learning in Octopus vulgaris. Science 256:545-547. https://doi.org/10.1126/science.256.5056.545

Gabay S, Leibovich T, Ben-Simon A, Henik A, Segev R (2013) Inhibition of return in the archer fish. Nat Commun 4:1657. https://doi.org/10.1038/ncomms 2644

Gajdon GK, Fijn N, Huber L (2004) Testing social learning in a wild mountain parrot, the kea (Nestor notabilis). Anim Learn Behav 32: 62-71. https://doi.org/10.3758/BF03196007

Gerullis P, Schuster S (2014) Archerfish actively control the hydrodynamics of their jets. Curr Biol 24:2156-2160. https://doi.org/10. 1016/j.cub.2014.07.059

Gómez-Laplaza LM, Morgan E (1986) Towards an isolation syndrome for the angelfish, Pterophyllum scalare. J Fish Biol 29:179-187. https://doi.org/10.1111/j.1095-8649.1986.tb05009.x

González-Bernal E, Brown GP, Shine R (2014) Invasive cane toads: social facilitation depends upon an individual's personality. PLOS ONE 9:e102880. https://doi.org/10.1371/journal.pone.0102880

Grampp M, Sueur C, van de Waal E, Botting J (2019) Social attention biases in juvenile wild vervet monkeys: implications for socialisation and social learning processes. Primates 60:261-275. https://doi.org/10.1007/s10329-019-00721-4

Greenberg R, Mettke-Hofmann C (2001) Ecological aspects of neophobia and neophilia in birds. In: Nolan V, Thompson CF (eds) Current ornithology. Springer US, Boston, MA, pp 119-178

Greggor AL, Thornton A, Clayton NS (2015) Neophobia is not only avoidance: improving neophobia tests by combining cognition and ecology. Curr Opin Behav Sci 6:82-89. https://doi.org/10.1016/j. cobeha.2015.10.007

Griffin AS, Guillette LM, Healy SD (2015) Cognition and personality: an analysis of an emerging field. Trends Ecol Evol 30:207-214. https:// doi.org/10.1016/j.tree.2015.01.012

Guenther A, Brust V, Dersen M, Trillmich F (2014) Learning and personality types are related in cavies (Cavia aperea). J Comp Psychol 128:74-81. https://doi.org/10.1037/a0033678

Guillette LM, Reddon AR, Hoeschele M, Sturdy CB (2011) Sometimes slower is better: slow-exploring birds are more sensitive to changes in a vocal discrimination task. Proc R Soc Lond B 278:767-773. https://doi.org/10.1098/rspb.2010.1669

Guillette LM, Hahn AH, Hoeschele M, Przyslupski A, Sturdy CB (2015) Individual differences in learning speed, performance accuracy and exploratory behaviour in black-capped chickadees. Anim Cogn 18: 165-178. https://doi.org/10.1007/s10071-014-0787-3

Guillette LM, Scott ACY, Healy SD (2016) Social learning in nestbuilding birds: a role for familiarity. Proc R Soc B 283:20152685. https://doi.org/10.1098/rspb.2015.2685

Hansen MJ, Ligocki IY, Zillig KE, Steel AE, Todgham AE, Fangue NA (2020) Risk-taking and locomotion in foraging threespine sticklebacks (Gasterosteus aculeatus): the effect of nutritional stress is 
dependent on social context. Behav Ecol Sociobiol 74:12. https:// doi.org/10.1007/s00265-019-2795-4

Heyes C (2012) What's social about social learning? J Comp Psychol 126:193-202. https://doi.org/10.1037/a0025180

Hoppitt WJE, Laland KN (2013) Social learning: an introduction to mechanisms, methods, and models. Princeton University Press, Princeton

Jarjour C, Evans JC, Routh M, Morand-Ferron J (2020) Does city life reduce neophobia? A study on wild black-capped chickadees. Behav Ecol 31:123-131. https://doi.org/10.1093/beheco/arz167

Jolles JW, Aaron Taylor B, Manica A (2016) Recent social conditions affect boldness repeatability in individual sticklebacks. Anim Behav 112:139-145. https://doi.org/10.1016/j.anbehav.2015.12.010

Jones NAR, Webster MM, Templeton CN, Schuster S, Rendell L (2018) Presence of an audience and consistent interindividual differences affect archerfish shooting behaviour. Anim Behav 141:95-103. https://doi.org/10.1016/j.anbehav.2018.04.024

Jones NAR, Webster MM, Newport C, Templeton CN, Schuster S, Rendell L (2020) Cognitive styles: speed-accuracy trade-offs underlie individual differences in archerfish. Anim Behav 160:1-14. https://doi.org/10.1016/j.anbehav.2019.11.019

Karoubi N, Leibovich T, Segev R (2017) Symbol-value association and discrimination in the archerfish. PLoS ONE 12:e0174044. https:// doi.org/10.1371/journal.pone.0174044

Kelly TR, Kimball MG, Stansberry KR, Lattin CR (2020) No, you go first: phenotype and social context affect house sparrow neophobia. Biol Lett 16:20200286. https://doi.org/10.1098/rsbl.2020.0286

Kent MIA, Burns AL, Figueira WF, Mazue GP, Porter AG, Wilson ADM, Ward AJW (2019) Risk balancing through selective use of social and physical information: a case study in the humbug damselfish. J Zool 308:235-242. https://doi.org/10.1111/jzo.12669

Koolhaas JM, Korte SM, De Boer SF, Van Der Vegt BJ, Van Reenen CJ, Hopster H, De Jong IC, Ruis MAW, Blokhuis HJ (1999) Coping styles in animals: current status in behavior and stress-physiology. Neurosci Biobehav Rev 23:925-935. https://doi.org/10.1016/ S0149-7634(99)00026-3

Krueger K, Farmer K, Heinze J (2014) The effects of age, rank and neophobia on social learning in horses. Anim Cogn 17:645-655. https://doi.org/10.1007/s10071-013-0696-x

Langley EJG, van Horik JO, Whiteside MA, Madden JR (2018) Individuals in larger groups are more successful on spatial discrimination tasks. Anim Behav 142:87-93. https://doi.org/10.1016/j. anbehav.2018.05.020

Laskowski KL, Bell AM (2013) Competition avoidance drives individual differences in response to a changing food resource in sticklebacks. Ecol Lett 16:746-753. https://doi.org/10.1111/ele.12105

Lima SL, Dill LM (1990) Behavioral decisions made under the risk of predation: a review and prospectus. Can J Zool 68:619-640. https:// doi.org/10.1139/z90-092

Lucon-Xiccato T, Montalbano G, Bertolucci C (2020) Personality traits covary with individual differences in inhibitory abilities in 2 species of fish. Curr Zool 66:187-195. https://doi.org/10.1093/cz/zoz039

Machnik P, Leupolz K, Feyl S, Schulze W, Schuster S (2018a) The Mauthner cell in a fish with top-performance and yet flexiblytuned C-starts I. Identification and comparative morphology. J Exp Biol 221:jeb.182535. https://doi.org/10.1242/jeb.182535

Machnik P, Leupolz K, Feyl S, Schulze W, Schuster S (2018b) The Mauthner cell in a fish with top-performance and yet flexiblytuned C-starts II. Physiology. J Exp Biol 221:jeb.175588. https:// doi.org/10.1242/jeb.175588

Mazza V, Eccard JA, Zaccaroni M, Jacob J, Dammhahn M (2018) The fast and the flexible: cognitive style drives individual variation in cognition in a small mammal. Anim Behav 137:119-132. https:// doi.org/10.1016/j.anbehav.2018.01.011

Mazza V, Dammhahn M, Eccard JA, Palme R, Zaccaroni M, Jacob J (2019) Coping with style: individual differences in responses to environmental variation. Behav Ecol Sociobiol 73:142. https://doi. org/10.1007/s00265-019-2760-2

McDonald ND, Rands SA, Hill F, Elder C, Ioannou CC (2016) Consensus and experience trump leadership, suppressing individual personality during social foraging. Sci Adv 2:e1600892. https://doi. org/10.1126/sciadv. 1600892

Mesquita FO, Borcato FL, Huntingford FA (2015) Cue-based and algorithmic learning in common carp: A possible link to stress coping style. Behav Process 115:25-29. https://doi.org/10.1016/j.beproc. 2015.02.017

Mettke-Hofmann C (2017) Neophobia. In: Vonk J, Shackelford T (eds) Encyclopedia of animal cognition and behavior. Springer International Publishing, Cham, pp 1-8

Mirville MO, Kelley JL, Ridley AR (2016) Group size and associative learning in the Australian magpie (Cracticus tibicen dorsalis). Behav Ecol Sociobiol 70:417-427. https://doi.org/10.1007/ s00265-016-2062-x

Morand-Ferron J, Cole EF, Quinn JL (2016) Studying the evolutionary ecology of cognition in the wild: a review of practical and conceptual challenges. Biol Rev 91:367-389. https://doi.org/10.1111/brv.12174

Newport C, Schuster S (2020) Archerfish vision: Visual challenges faced by a predator with a unique hunting technique. Semin Cell Dev Biol 106:53-60. https://doi.org/10.1016/j.semcdb.2020.05.017

Newport C, Wallis G, Temple SE, Siebeck UE (2013) Complex, contextdependent decision strategies of archerfish, Toxotes chatareus. Anim Behav 86:1265-1274. https://doi.org/10.1016/j.anbehav. 2013.09.031

Newport C, Wallis G, Siebeck UE (2014) Concept learning and the use of three common psychophysical paradigms in the archerfish (Toxotes chatareus). Front Neural Circuits 8:39. https://doi.org/10.3389/ fncir.2014.00039

Newport C, Wallis G, Siebeck UE (2018) Object recognition in fish: accurate discrimination across novel views of an unfamiliar object category (human faces). Anim Behav 145:39-49. https://doi.org/10. 1016/j.anbehav.2018.09.002

Nicol CJ, Pope SJ (1999) The effects of demonstrator social status and prior foraging success on social learning in laying hens. Anim Behav 57:163-171. https://doi.org/10.1006/anbe.1998.0920

O'Neill SJ, Williamson JE, Tosetto L, Brown C (2018) Effects of acclimatisation on behavioural repeatability in two behaviour assays of the guppy Poecilia reticulata. Behav Ecol Sociobiol 72:166. https:// doi.org/10.1007/s00265-018-2582-7

Patton BW, Braithwaite VA (2015) Changing tides: ecological and historical perspectives on fish cognition. Wiley Interdiscip Rev Cogn Sci 6:159-176. https://doi.org/10.1002/wcs.1337

Pearish S, Bensky MK, Bell AM (2019) Social environment determines the effect of boldness and activity on survival. Ethology 125:855862. https://doi.org/10.1111/eth.12939

Pendergraft LT, Lehnert AL, Marzluff JM (2020) Individual and social factors affecting the ability of American crows to solve and master a string pulling task. Ethology 126:229-245. https://doi.org/10.1111/ eth. 12980

Pritchard DJ, Hurly TA, Tello-Ramos MC, Healy SD (2016) Why study cognition in the wild (and how to test it)? J Exp Anal Behav 105:4155. https://doi.org/10.1002/jeab.195

R Core Team (2019) R: A language and environment for statistical computing. R Foundation for Statistical Computing, Vienna, Austria http://www.R-project.org

Raoult V, Trompf L, Williamson JE, Brown C (2017) Stress profile influences learning approach in a marine fish. PeerJ 5:e3445. https://doi.org/10.7717/peerj.3445

Reader SM (2015) Causes of individual differences in animal exploration and search. Top Cogn Sci 7:451-468. https://doi.org/10.1111/tops.12148

Reader SM (2016) Animal social learning: associations and adaptations. F1000Research 5:2120. https://doi.org/10.12688/f1000research.7922.1 
Reinel CP, Schuster S (2018) Rapid depth perception in hunting archerfish I. The predictive C-starts use an independent estimate of target height. J Exp Biol 221:jeb.177345. https://doi.org/10.1242/jeb.177345

Riley JL, Noble DWA, Byrne RW, Whiting MJ (2017) Does social environment influence learning ability in a family-living lizard? Anim Cogn 20:449-458. https://doi.org/10.1007/s10071-016-1068-0

Riley JL, Küchler A, Damasio T, Noble DWA, Byrne RW, Whiting MJ (2018) Learning ability is unaffected by isolation rearing in a familyliving lizard. Behav Ecol Sociobiol 72:20. https://doi.org/10.1007/ s00265-017-2435-9

Rischawy I, Schuster S (2013) Visual search in hunting archerfish shares all hallmarks of human performance. J Exp Biol 216:3096-3103. https://doi.org/10.1242/jeb.087734

Rischawy I, Blum M, Schuster S (2015) Competition drives sophisticated hunting skills of archerfish in the wild. Curr Biol 25:R595-R597. https://doi.org/10.1016/j.cub.2015.06.005

Rowe C, Healy SD (2014) Measuring variation in cognition. Behav Ecol 25:1287-1292. https://doi.org/10.1093/beheco/aru090

Schlegel T, Schuster S (2008) Small circuits for large tasks: high-speed decision-making in archerfish. Science 319:104-106. https://doi. org/10.1126/science. 1149265

Schuster S (2007) Archerfish. Curr Biol 17:R494-R495. https://doi.org/ 10.1016/j.cub.2007.04.014

Schuster S, Wöhl S, Griebsch M, Klostermeier I (2006) Animal cognition: how archer fish learn to down rapidly moving targets. Curr Biol 16:378-383. https://doi.org/10.1016/j.cub.2005.12.037

Seferta A, Guay P-J, Marzinotto E, Lefebvre L (2001) Learning differences between feral pigeons and Zenaida doves: the role of neophobia and human proximity. Ethology 107:281-293. https:// doi.org/10.1046/j.1439-0310.2001.00658.x

Sherwin CM (2003) Social context affects the motivation of laboratory mice, Mus musculus, to gain access to resources. Anim Behav 66: 649-655. https://doi.org/10.1006/anbe.2003.2239

Shettleworth SJ (1972) Constraints on learning. Adv Stud Behav 4:1-68. https://doi.org/10.1016/S0065-3454(08)60006-6

Shettleworth SJ (2009) Cognition, evolution, and behavior, 2nd edn. Oxford University Press, New York

Sih A, Del Giudice M (2012) Linking behavioural syndromes and cognition: a behavioural ecology perspective. Phil Trans R Soc B 367: 2762-2772. https://doi.org/10.1098/rstb.2012.0216

Simon KD, Bakar Y, Temple SE, Mazlan AG (2011) Spitting success and accuracy in archer fishes Toxotes chatareus (Hamilton, 1822) and Toxotes jaculatrix (Pallas, 1767). Sci Res Essays 6:1627-1633. https://doi.org/10.5897/SRE11.033

Smit JAH, van Oers K (2019) Personality types vary in their personal and social information use. Anim Behav 151:185-193. https://doi.org/ 10.1016/j.anbehav.2019.02.002

Smith TE, McGreer-Whitworth B, French JA (1998) Close proximity of the heterosexual partner reduces the physiological and behavioral consequences of novel-cage housing in black tufted-ear marmosets (Callithrix kuhli). Horm Behav 34:211-222. https://doi.org/10. 1006/hbeh.1998.1469

Snijders L, Kurvers RHJM, Krause S, Tump AN, Ramnarine IW, Krause $\mathrm{J}$ (2019) Females facilitate male food patch discovery in a wild fish population. J Anim Ecol 88:1950-1960. https://doi.org/10.1111/ 1365-2656.13086

Soma M, Hasegawa T (2004) The effect of social facilitation and social dominance on foraging success of budgerigars in an unfamiliar environment. Behaviour 141:1121-1134. https://doi.org/10.1163/ 1568539042664560

Strand DA, Utne-Palm AC, Jakobsen PJ, Braithwaite VA, Jensen KH, Salvanes AGV (2010) Enrichment promotes learning in fish. Mar Ecol Prog Ser 412:273-282. https://doi.org/10.3354/meps08682

Svanbäck R, Bolnick DI (2007) Intraspecific competition drives increased resource use diversity within a natural population. Proc $\mathrm{R}$ Soc Lond B 274:839-844. https://doi.org/10.1098/rspb.2006.0198
Szabo B, Bugnyar T, Auersperg AMI (2017) Within-group relationships and lack of social enhancement during object manipulation in captive Goffin's cockatoos (Cacatua goffiniana). Learn Behav 45:719. https://doi.org/10.3758/s13420-016-0235-0

Szopa-Comley AW, Donald WG, Ioannou CC (2020a) Predator personality and prey detection: inter-individual variation in responses to cryptic and conspicuous prey. Behav Ecol Sociobiol 74:70. https:// doi.org/10.1007/s00265-020-02854-9

Szopa-Comley AW, Duffield C, Ramnarine IW, Ioannou CC (2020b) Predatory behaviour as a personality trait in a wild fish population. Anim Behav 170:51-64. https://doi.org/10.1016/j.anbehav.2020. 10.002

Temple S, Hart NS, Marshall NJ, Collin SP (2010) A spitting image: specializations in archerfish eyes for vision at the interface between air and water. Proc R Soc Lond B 277:2607-2615. https://doi.org/ $10.1098 / \mathrm{rspb} .2010 .0345$

Therneau TM (2019) survival: survival analysis. Version 3:1-8 https:// CRAN.R-project.org/package $=$ survival

Timmermans PJA, Maris E (2000) Does the bright spot on the back of young archer fishes serve group coherence? Neth J Zool 50:401409. https://doi.org/10.1163/156854200X00153

Timmermans PJA, Vossen JMH (2000) Prey catching in the archer fish: does the fish use a learned correction for refraction? Behav Process 52:21-34. https://doi.org/10.1016/S0376-6357(00)00107-8

Tucker EK, Suski CD (2019) Presence of conspecifics reduces betweenindividual variation and increases avoidance of multiple stressors in bluegill. Anim Behav 158:15-24. https://doi.org/10.1016/j.anbehav. 2019.10.002

Vila Pouca C, Brown C (2019) Lack of social preference between unfamiliar and familiar juvenile Port Jackson sharks Heterodontus portusjacksoni. J Fish Biol 95:520-526. https://doi.org/10.1111/ jfb.13982

Vila Pouca C, Heinrich D, Huveneers C, Brown C (2020) Social learning in solitary juvenile sharks. Anim Behav 159:21-27. https://doi.org/ 10.1016/j.anbehav.2019.10.017

Visalberghi E, Fragaszy D (1995) The behaviour of capuchin monkeys, Cebus apella, with novel food: the role of social context. Anim Behav 49:1089-1095. https://doi.org/10.1006/anbe.1995.0137

Ward AJW, Webster MM (2016) Sociality: the behaviour of group living animals. Springer Academic Publishing, Cham

Webster MM, Laland KN (2012) Social information, conformity and the opportunity costs paid by foraging fish. Behav Ecol Sociobiol 66: 797-809. https://doi.org/10.1007/s00265-012-1328-1

Webster MM, Laland KN (2017) Social information use and social learning in non-grouping fishes. Behav Ecol 28:1547-1552. https://doi. org/10.1093/beheco/arx121

Webster MM, Laland KN (2018) Experience shapes social information use in foraging fish. Anim Behav 146:63-70. https://doi.org/10. 1016/j.anbehav.2018.10.005

Webster MM, Rutz C (2020) How STRANGE are your study animals? Nature 582:337-340. https://doi.org/10.1038/d41586-020-01751-5

Webster MM, Ward AJW (2011) Personality and social context. Biol Rev 86:759-773. https://doi.org/10.1111/j.1469-185X.2010.00169.x

Webster MM, Ward AJW, Hart PJB (2007) Boldness is influenced by social context in threespine sticklebacks (Gasterosteus aculeatus). Behaviour 144:351-371. https://doi.org/10.1163/ 156853907780425721

Webster MM, Chouinard-Thuly L, Herczeg G, Kitano J, Riley R, Rogers S, Shapiro MD, Shikano T, Laland KN (2019) A four-questions perspective on public information use in sticklebacks (Gasterosteidae). R Soc Open Sci 6:181735. https://doi.org/10. 1098/rsos. 181735

White LJ, Thomson JS, Pounder KC, Coleman RC, Sneddon LU (2017) The impact of social context on behaviour and the recovery from welfare challenges in zebrafish, Danio rerio. Anim Behav 132:189 199. https://doi.org/10.1016/j.anbehav.2017.08.017 
Zajonc RB, Heingartner A, Herman EM (1969) Social enhancement and impairment of performance in the cockroach. J Pers Soc Psychol 13: 83-92. https://doi.org/10.1037/h0028063

Zentall TR, Hogan DE (1976) Imitation and social facilitation in the pigeon. Anim Learn Behav 4:427-430. https://doi.org/10.3758/ BF03214434

Zidar J, Balogh A, Favati A, Jensen P, Leimar O, Løvlie H (2017) A comparison of animal personality and coping styles in the red junglefowl. Anim Behav 130:209-220. https://doi.org/10.1016/j. anbehav.2017.06.024

Publisher's note Springer Nature remains neutral with regard to jurisdictional claims in published maps and institutional affiliations. 